\title{
Das escavações à sociedade: a divulgação científica sob a ótica das crianças de Peirópolis
}

Simone Bortoliero

Doutora em Comunicação Científica (UMESP/SP).

Professora da Faculdade de Comunicação da Universidade Federal da Bahia, BA.

E-mail: bortolie@ufba.br

Nelson Rui Ribas Bejarano

Doutor em Educação/Ensino de Ciências (FE/USP). Professor do Instituto de Química da Universidade Federal da Bahia, BA.

E-mail: bejarano@ufba.br

Érika Hinkle

Doutora em Arte Educação (EUA). Professora do Curso de Comunicação da

Universidade de Uberaba, $M G$.

E-mail: erika.hinkle@uniube.br

Embora em determinadas épocas da história os conceitos de Arte e de Ciência tenham sido rotulados como "opostos", hoje é cada vez mais difícil negar a delicada teia de inter-relação que existe entre eles. Criação vista como fantasia ou devaneio da imaginação, conota o irreal, o não-existente, o impossível, o lúdico, o pouco objetivo e no mínimo o não-científico. Porém, não podemos esquecer que entre as maiores descobertas da ciência, de forma estreita e irredutível, Einstein, Freud e Plank pouco teriam conquistado se não possuíssem notáveis doses dessas qualidades consideradas não muito científicas. Por outro lado, artistas como Da Vinci e Picasso também quase nada alcançariam se não possuíssem qualidades consideradas inerentes e indispensáveis à Ciência, como perseverança, método e técnica.

A partir do final da década de 1970 e início da de 1980, a comunidade de pesquisadores internacionais em ensino de ciências começou a investir no desenvolvimento de uma promissora linha de pesquisa, a qual buscava inventariar o entendimento particular de conceitos científicos que os alunos traziam para as aulas de ciências, antes mesmo de terem entrado em contato com esses juízos formalmente nas suas escolas. 
Nesses estudos, verificou-se que os alunos traziam para as aulas de ciências conhecimentos bem elaborados sob uma vasta gama de conceitos científicos. Os professores passaram a perceber, estarrecidos, que eles tinham construído idéias de conceitos como força, átomo, elétrons, eletricidade, célula, microorganismo, fotossíntese, osmose, reação química, digestão dos alimentos, a origem do universo, o movimento dos planetas, as estrelas, só para citar alguns e mostrar que por extensão os alunos podem perfeitamente ter uma concepção particular sobre qualquer aspecto do conhecimento científico acumulado pela humanidade.

Durante vinte anos o principal esforço de pesquisadores foi fazer um cuidadoso levantamento de como as crianças, de diferentes contextos, compreendiam os mesmos conceitos científicos. Logo se pôde concluir que, a despeito de morarem em diferentes países ou até continentes, basicamente suas concepções alternativas eram semelhantes. Uma explicação possível para esse fato pode ser o de que a natureza, que funciona como um laboratório para as crianças criarem suas concepções, é a mesma em diferentes países. Aqui já se está assumindo que as crianças funcionam como cientistas na medida em que usam o ambiente natural para construir suas concepções, fazer experimentações, formular hipóteses e dessa forma ir construindo suas explicações para os fenômenos naturais.

Portanto, neste início de século, em que as inovações tecnológicas são fontes inesgotáveis de informação para nossos jovens, é justo um olhar cuidadoso sobre como eles querem participar de uma ciência cidadã, ouvir suas opiniões sobre quais informações científicas gostariam de ver divulgadas e como promover o conhecimento em prol da democracia.

\section{OBSERVANDO OS AMADORES DA CIÊNCIA}

Com o intuito de fazer um levantamento nacional dos jovens "amadores da ciência”, conceito abordado pelo físico e divulgador científico Freeman Dyson ${ }^{1}$, que vem estudando como a ciência pode ser importante na vida dos não-cientistas, passamos a observar a realidade de algumas pesquisas em andamento nas universidades brasileiras e encontramos uma série de atividades de campo, em que pesquisadores de áreas distintas realizam seus trabalhos de forma sistemática apoiados por comunidades espalhadas nas diferentes regiões do país. Localizamos pesquisas no campo da paleontologia, na região do Triângulo Mineiro em Minas Gerais, onde geólogos e paleontólogos fazem escavações diante dos "olhares curiosos" de inúmeros jovens e crianças que vivem no campo.

As relações entre a pesquisa acadêmica e as comunidades, e a produção de vídeos de divulgação da ciência sob a ótica das concepções científicas de

DYSON, Freeman J. O sol, o genoma e a internet: ferramentas das revoluções científicas. São Paulo: Companhia das Letras, 2001. jovens de área rural foram centrais em nossas investigações durante os anos de 2001 e 2002 em Peirópolis, bairro distante $30 \mathrm{~km}$ da cidade de Uberaba, no Triângulo Mineiro. Identificamos inicialmente que os jovens sujeitos da pesquisa, matriculados na escola Frederico Peiró, recebiam os conteúdos científicos somente através dos livros didáticos nas aulas de ciências e geografia, 
um conteúdo distanciado da realidade regional.

As influências das pesquisas paleontológicas na comunidade de Peirópolis, principalmente as relacionadas à geração de empregos e à melhoria da qualidade de vida, permitiram um direcionamento em nossos objetivos de pesquisa. Não investigamos se o conhecimento sobre paleontologia favoreceu as mudanças conceituais das concepções desses jovens, mas identificamos a necessidade de que os pesquisadores distribuídos em todo o país, independentemente dos objetivos de seus trabalhos acadêmicos, devem estabelecer formas de diálogo com as populações onde estão inseridos, numa perspectiva de divulgar, democratizar e colocar seus achados, suas descobertas, seus conhecimentos a serviço da melhoria da qualidade de vida de tais populações. Dessa forma, teríamos um compromisso dos pesquisadores brasileiros com a educação científica através das ações concretas das pesquisas, principalmente onde há atividades de campo.

Nessa primeira fase nossos estudos se concentraram na região do cerrado mineiro. Tivemos como resultado alguns vídeos de divulgação científica elaborados por adolescentes. A produção de vídeos no campo da popularização de temas científicos geralmente vem sendo realizada por grupos isolados no país, ora por meio de consultores científicos das universidades com o intuito de veiculação via redes de televisão, ora como produto didático-pedagógico utilizado por professores de ciências no ensino fundamental dentro das salas de aula, ora como resultado de projetos de conclusão de cursos de jornalismo. Nos programas de televisão geralmente temos a participação de jornalistas, de produtores e de comunicadores especializados em assuntos de ciência e tecnologia. Esses profissionais fazem parte do grupo de divulgadores científicos no país, que reúne desde os professores de ciências, físicos, matemáticos, biólogos, geógrafos, até historiadores, músicos, artistas, representantes de museus, amantes da ciência, representantes de órgãos de pesquisa, entre outros. Como exemplo desse conjunto de pessoas que comungam da idéia de que é necessário popularizar a ciência, em fevereiro de 2004 tivemos quase 4 mil pessoas, orientadas por um carnavalesco assessorado por professores da Universidade Federal do Rio de Janeiro, desfilando as ciências naturais no sambódromo do Rio de Janeiro, tendo a Unidos da Tijuca recebido o segundo lugar no Carnaval.

Por outro lado, já existe de forma sistematizada um conjunto de pesquisas no campo da Comunicação Científica, e aqui falamos da contribuição dos jornalistas, tornando possível reflexões sobre maior acesso às informações científicas pelas populações excluídas. E nesse aspecto é fundamental a contribuição de André Giordan, quando afirma que jornalistas que atuam em divulgação científica ganhariam se estudassem um pouco mais de perto as representações científicas dos jovens e os obstáculos que estas traduzem, antes de considerarem apenas o conteúdo e as formas da mensagem que desejam passar².

Com essas incursões no campo da educação, fizemos novas abordagens e, assim, traçamos um diagnóstico das histórias de vida do lugar. Ouvimos com atenção o entendimento dos jovens sobre o meio ambiente nas dimensões cultural e social. Verificamos um certo grau de compreensão sobre os processos e dificuldades
2. GIORDAN, A.; DE VEC$\mathrm{CHI}, \mathrm{G}$. As origens do saber: das concepções dos aprendentes aos conceitos científicos. 2. ed. Trad. Bruno Charles Magne. Porto Alegre: Artes Médicas, 1996. p. 215. 
que envolvem a pesquisa paleontológica. Gravamos as diversas visões acerca da ciência dentro da comunidade e tivemos a preocupação com a documentação da cultura da região, além de levarmos em consideração os saberes trazidos da trajetória pessoal de cada jovem para a produção de material audiovisual, com o objetivo de democratizar conhecimentos, seja científicos, seja populares. No decorrer das atividades, percebemos algumas mudanças pedagógicas no âmbito escolar quanto ao uso de novas tecnologias. Neste artigo, apresentamos apenas uma parte da pesquisa nacional - intitulada "Do mar, da terra e do ar para a Sociedade. A divulgação científica sob a ótica dos jovens amadores da ciência" -, a qual visa identificar os jovens amadores da ciência no cerrado mineiro (estudos de paleontologia, geologia e geografia), no pantanal do Mato Grosso (estudos de peixes e grandes vertebrados), no litoral norte (estudo de animais marinhos e zona costeira), na Chapada Diamantina (estudo de cavernas e astronomia) e na floresta amazônica (estudos de rios, espécies de plantas e animais).

\section{QUESTÕES E OBJETIVOS DE PESQUISA}

- Contribuir com o desenvolvimento de uma cultura científica e artística na região de Uberaba, particularmente com crianças do ensino fundamental da escola Frederico Peiró, no bairro de Peirópolis, local conhecido pelas descobertas paleontológicas desde a década de 1940. As pesquisas paleontológicas possibilitaram a inauguração de um Museu dos Dinossauros de Peirópolis (MDiP) ${ }^{3}$ em meados dos anos de 1990, com coleções de fósseis encontrados na região e aberto à visitação pública diariamente.

- Produzir animações e vídeos de divulgação científica sob a ótica das concepções científicas desses jovens.

3. <http://acd.ufrj.br/geologia/sbp/ceprice.htm>.

4. <http://www.icom.org.br/>.

5. BEJARANO, N. R. Avaliação qualitativa em processos não-formais do ensino de ciências: o museu dinâmico de ciências de Campinas. SP/Campinas: Unicamp, Faculdade de Educação, 1994. 141 p. Dissertação de Mestrado em Educação.

\section{UMA PEQUENA APRESENTAÇÃO DO MUSEU DOS DINOSSAUROS DE PEIRÓPOLIS}

O conceito de museus tem evoluído rapidamente através dos tempos. Desde os museus de caráter privado da idade média, que eram, no geral, resultantes de saques de guerras, passando pelos primeiros museus de caráter público, exemplificados na concepção do museu do Louvre. O conceito moderno estabelecido pelo ICOM - Conselho Internacional de Museus ${ }^{4}$, organização nãogovernamental apoiada pela UNESCO, alarga sobremaneira a própria idéia do museu público. Pode-se considerar como museus espaços como um oceanário, uma reserva ecológica, um jardim botânico ou simplesmente um zoológico ${ }^{5}$.

Nesse sentido, o Museu dos Dinossauros da comunidade de Peirópolis é identificado mais no sentido tradicional do conceito, apesar de possuir um centro de pesquisas paleontológicas de referência internacional como parte de seus equipamentos. O museu oferece como atração pública uma coleção de fósseis de vertebrados de vários períodos, chegando a peças com datação confirmada de oitenta milhões 
de anos. O seu caráter tradicional é ter à disposição dos visitantes as coleções de fósseis, tanto para o público escolarizado como o geral. O maior número de fósseis encontrados é de répteis, como grandes tartarugas e espécies de crocodilianos - semelhantes aos jacarés. Foram encontrados três grupos de dinossauros: o Titanossauro, herbívoro de grande porte, um carnívoro do grupo dos Carnossauros e um de menor porte e bastante ágil conhecido com Celurossauro.

A exploração, datação e classificação dos fósseis no museu foi uma luta da comunidade de Peirópolis, em meados da década de 1990. A exploração teve início em 1944, com o paleontólogo Llewellyn Ivor Price, contratado nesse período pelo Ministério da Agricultura. De fato, todos os fósseis encontrados, entre 1944 e o final da década de 1980, eram enviados a outros centros de pesquisa e museus nacionais e internacionais. Uma das atividades importantes desenvolvidas no museu a partir de 2000 é a união entre a arte e a educação científica. Durante as visitações escolares, os alunos são convidados a realizar atividades de desenho, manipulação de argila, produção de textos, sempre dentro da temática relacionada aos dinossauros. Foi com base na observação dessas atividades que tivemos a idéia de propor aos jovens participantes da pesquisa o uso do desenho como forma de documentar e registrar as concepções científicas acerca da origem da Terra, origem e desaparecimento dos dinossauros e vida dos animais rurais. Em 2005 iniciamos uma nova pesquisa com jovens de áreas rurais no município de Seabra, na Chapada Diamantina, região de cavernas, onde estamos implementando um Centro de Ciências com apoio da FINEP. A mesma metodologia utilizada em Peirópolis também está sendo empregada com jovens marisqueiros na comunidade de Baiacu, na Ilha de Itaparica, no Estado da Bahia.

\section{A TRAJETÓRIA E O CONTEXTO DA INVESTIGAÇÃO}

A escola Frederico Peiró teve seus alunos escolhidos dentre todas as escolas que habitualmente visitam o museu, na qualidade de sujeitos dessa pesquisa.

Está localizada numa comunidade onde vivem aproximadamente duzentos habitantes. Seus alunos residem em sítios próximos da escola. A renda familiar deriva de hortas, pomares, criação de animais, venda de leite e derivados, tudo numa escala de pequenos produtores.

Até o início da pesquisa, a escola Frederico Peiró não tinha vínculos estáveis com o museu, embora a separação física entre os dois seja inferior a 500 metros. Foi escolhida uma única classe de 15 alunos, na faixa etária entre 12 e 16 anos, formalmente matriculados na sexta série do ensino fundamental. Com o grupo de estudantes, estiveram presentes nas atividades da pesquisa as professoras de Ciências, Geografia e Português ${ }^{6}$. Da equipe do museu a participação mais ativa se deu através de uma pedagoga e de um guia, estudante do curso de Geografia e funcionário do museu. Dentro do grupo de pesquisadores contávamos com uma equipe multidisciplinar composta por um pesquisador de cada uma das áreas de Arte-Educação, Comunicação Científica e Educação em Ciências, respectivamente professores da Universidade de Uberaba e da Universidade Federal de Uberlândia.
6. BOGDAN, R. C.; BIKLEN, S. K. Qualitative research for education: introduction to theory and methods (Pesquisa qualitativa para educação: introdução para teoria e métodos). Boston: Ally and Bacon, 1982. 
O financiamento do Museu dos Dinossauros se dá mediante verbas da Prefeitura Municipal de Uberaba, da FAPEMIG ${ }^{7}$ (Fundação de Apoio à Pesquisa do Estado de Minas Gerais) e da Faculdade de Educação de Uberaba.

$\mathrm{O}$ trabalho de pesquisa propriamente dito foi pensado de maneira que contemplasse quatro temas. Duas dessas temáticas, "A origem da Terra" e "A origem dos dinossauros e seu desaparecimento", são atividades desenvolvidas pelo museu com as escolas visitantes. O terceiro tema, "A vida de animais rurais", derivou de uma preocupação dos sujeitos da pesquisa e um quarto tema, de nossa própria investigação: as influências dessas pesquisas paleontológicas na construção das concepções científicas dos jovens.

Como hipótese central de trabalho acreditávamos a priori que a atividade de escavação que dá origem à descoberta de fósseis pudesse influenciar na construção de concepções, entre a população escolar, tanto de aspectos ambientais - do ponto de vista geológico, a formação de rios, lagos, cachoeiras e mares primitivos, a origem e extinção dos dinossauros, familiaridade com a atividade científica específica da paleontologia - quanto histórico-culturais relativos à formação dessa comunidade de Peirópolis. Para tanto, foram propostas várias atividades simultâneas que compõem a estrutura fundamental da investigação.

\section{Atividade 1:}

Convidamos nossos sujeitos a desenharem temas como a origem da Terra, o surgimento e o desaparecimento dos dinossauros e o que conheciam da história da comunidade em que viviam, usando materiais simples como lápis preto e colorido, canetas hidrocor e folhas de papel do tamanho ofício. Isso constituiu o primeiro registro. Cada um dos participantes realizou três desenhos, um de cada tema proposto.

\section{Atividade 2:}

Propusemos aos participantes desenhar as mesmas temáticas, agora a partir de orientações (palestras) de caráter científico desenvolvidas pela equipe técnica do museu, podendo o grupo questionar livremente os temas propostos. Nesta atividade implementamos o conceito de entrevista coletiva, em que os alunos exercem o papel de "repórteres científicomirins" e o guia (corpo técnico) assume o papel de pesquisador como fonte fidedigna de informação.

\section{Atividade 3:}

Visita de todo o grupo ao local de escavações paleontológicas. A atividade foi preparada dentro das aulas de Ciências, Geografia e Português e definiu objetivos em comum, como: coleta de rochas para formação de um museu de rochas e minerais na escola; observação do comportamento de insetos e pequenas aves e de alguns outros animais; coleta de plantas 
para formação de um herbário na escola e construção de uma lupa para observação de animais.

\section{ATIVIDADE 4:}

Treinamento técnico e operacional de três jovens, objetivando o domínio de gravação de imagens em equipamento digital (câmera JVC digital, formato mini-DV). Outros três jovens foram treinados como repórteres científico-mirins ${ }^{8}$. Numa segunda fase do treinamento, o grupo foi dividido em três subgrupos com o intuito de levantar temáticas relacionadas ao ambiente em que vivem. Como resultado inicial, as primeiras idéias foram associadas a dinossauros, astronomia e reprodução de orquídeas. Num segundo momento, a escolha definitiva recaiu, após negociação do grupo, sobre três temas: dinossauros, águas de Peirópolis e mundo rural, que deram origem aos vídeos de divulgação científica.

Demonstrativo da EVOluÇÃo dos CONHECIMENTOS E PERCEPÇÃo ARTíStica E CiENTífica duRANTE a PESQUisa, REVElados atraVÉS dos DESENHOS.

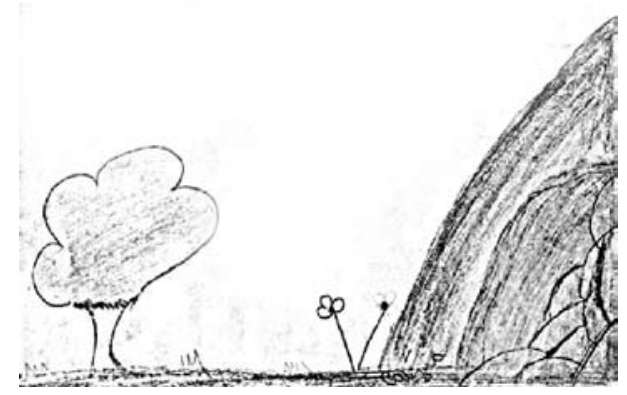

(FASE INICIAL)
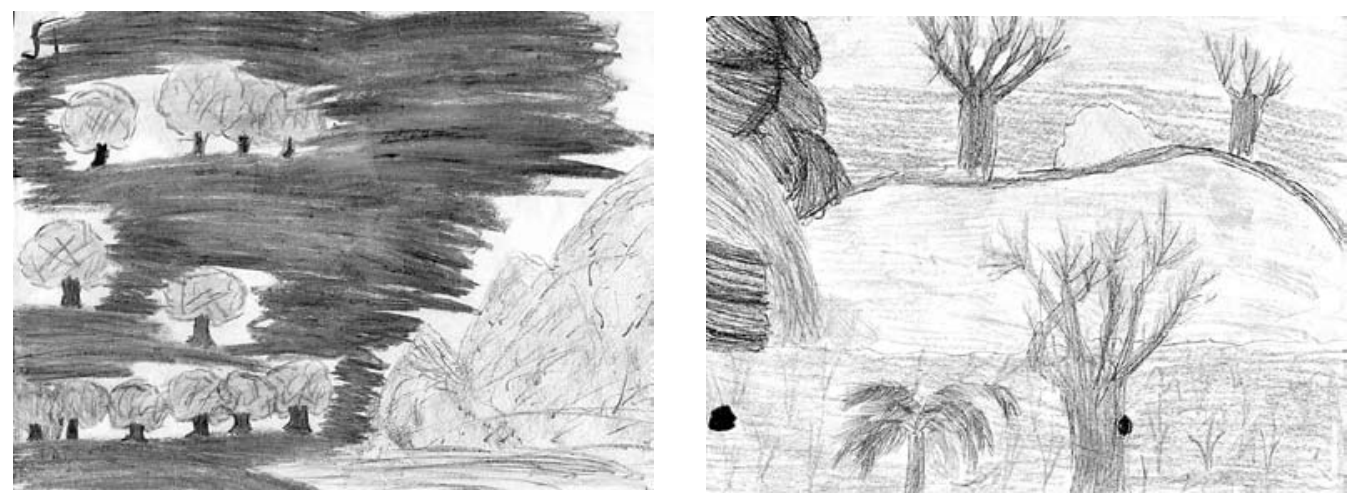

(FASE INTERMEDIÁRIA)

Do início do trabalho até o final da pesquisa, altera-se a representação da natureza pelo aluno. O aluno passa a representar o meio ambiente com mais cuidado, revela a vegetação local (coqueiros) e uma grande área verde. Além de representar as águas e cachoeiras do lugar. Os desenhos demonstram a ampliação do conhecimento científico $e$ da conscientização da área científica.

8. ARMES, R. On video: o significado do vídeo nos meios de comunicação. São Paulo: Summus, 1999. 
comunicação \& educação • Ano X • Número 3 - set/dez 2005

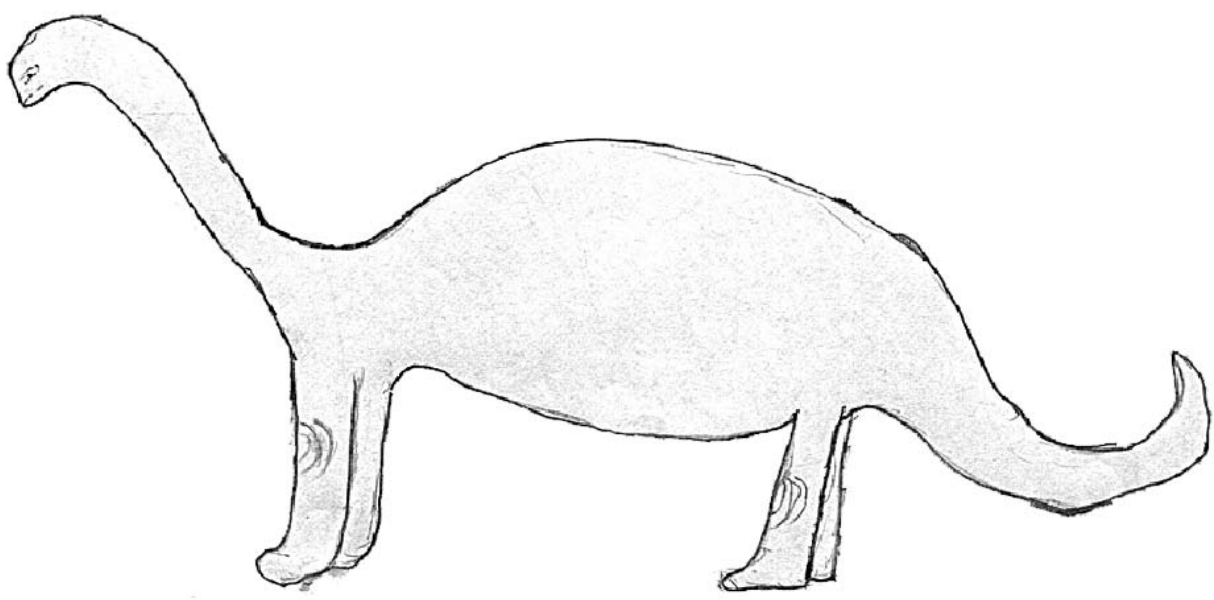

Estereótipo representando o dinossauro visto na parte externa do Museu.
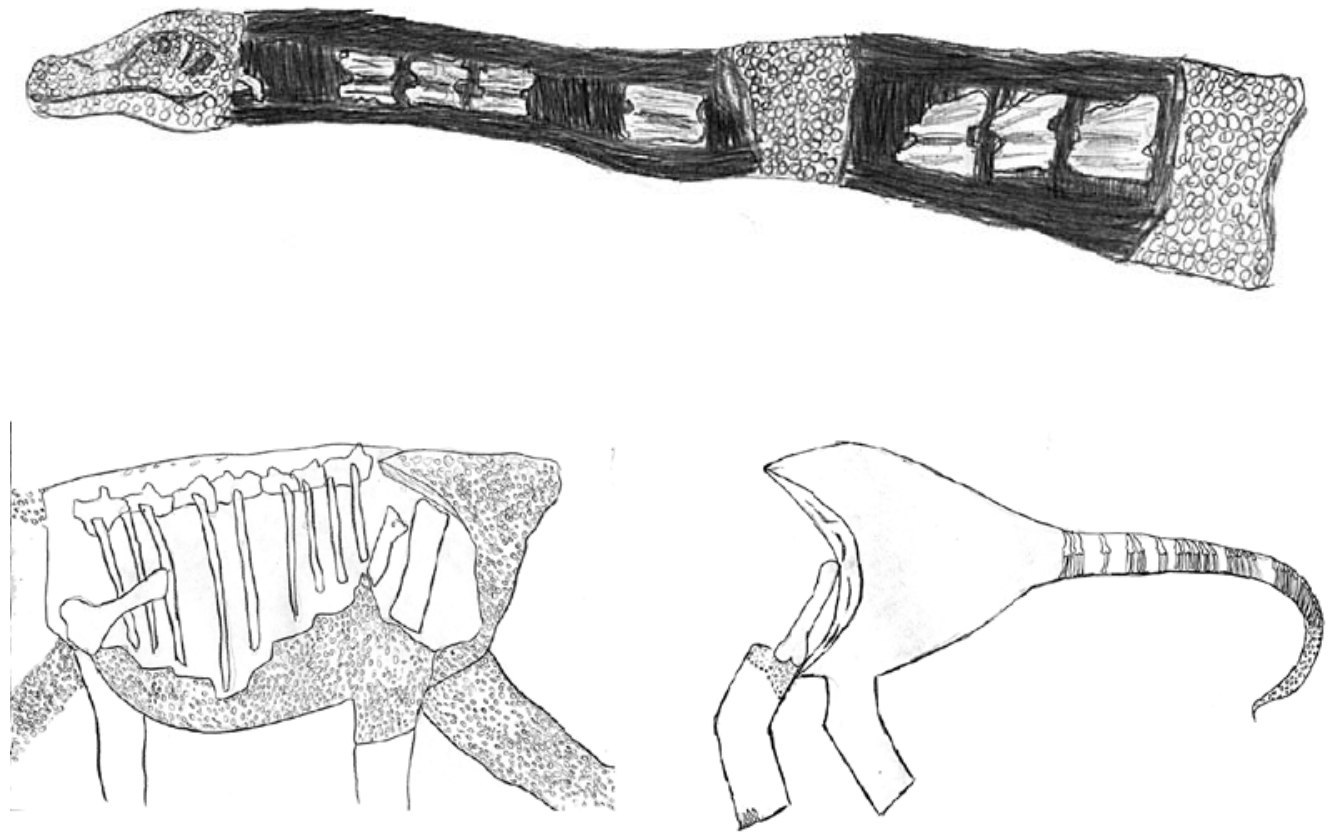

Evolução do conhecimento após os estudos sobre os esqueletos, a relação entre esqueletos dos animais domésticos e os dinossauros e as visitas mais detalhadas ao Museu. 


\author{
A ORIGEM DA TERRA
}

E A EVOLUÇÃO DA VIDA
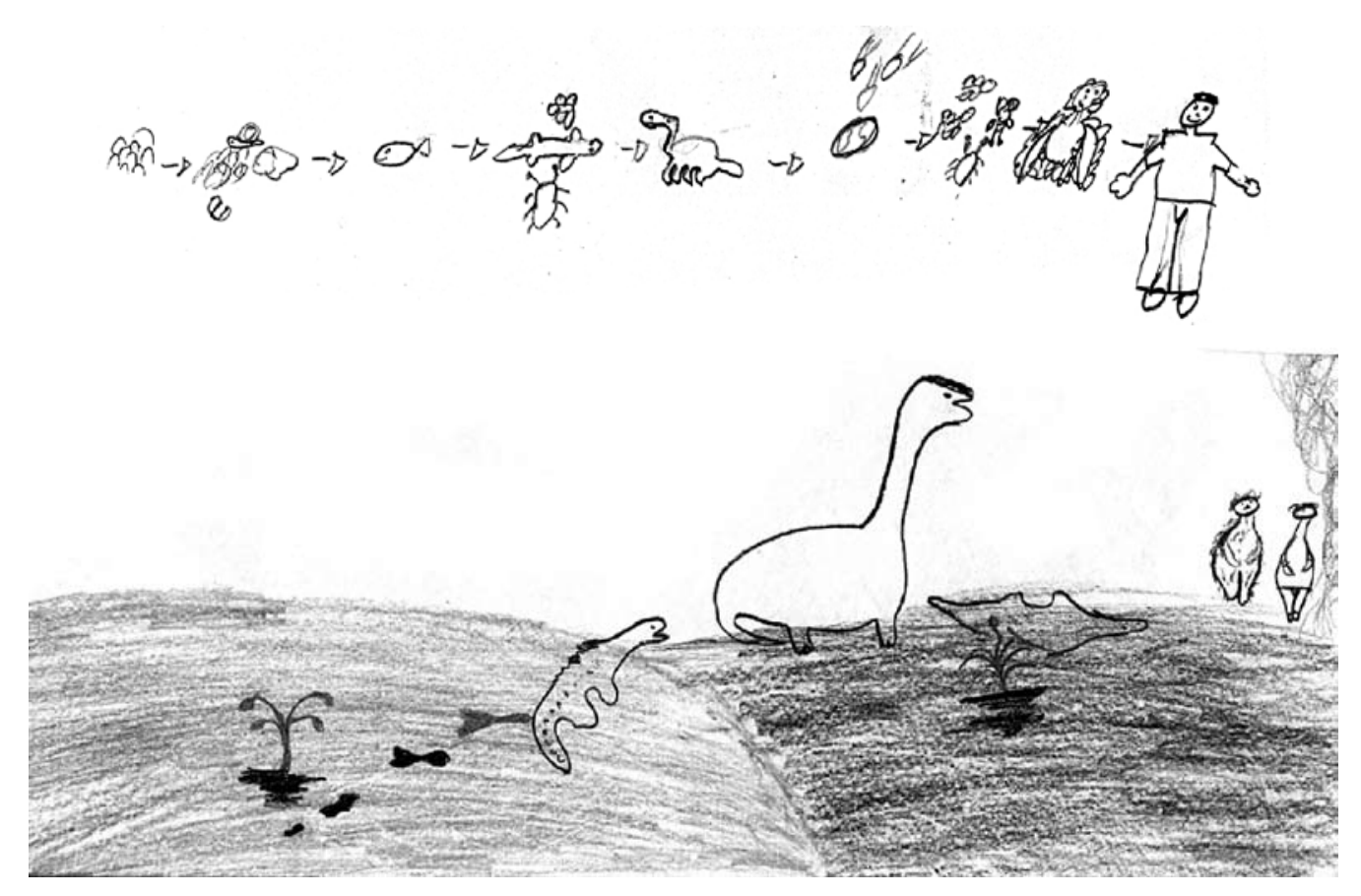

Após os estudos sobre a origem da terra, a evolução da vida, das plantas e dos seres, os alunos representam através dos desenhos as concepções aprendidas e demonstram uma maior compreensão da evolução do universo, onde plantas, seres vivos e animais fazem parte do todo e do processo de evolução do homem. Nestes desenhos, observa-se a evolução através do movimento, da sequência lógica do pensamento, a presença do fator "tempo", o que depois será trabalhado com maior profundidade e transformado os desenhos estáticos em animação.

\title{
Detalhes observados pelos alunos no SEu cotidiano, REVELADOS NOS QUADROS SEQÜENCIAIS DAS ANIMAÇÕES.
}

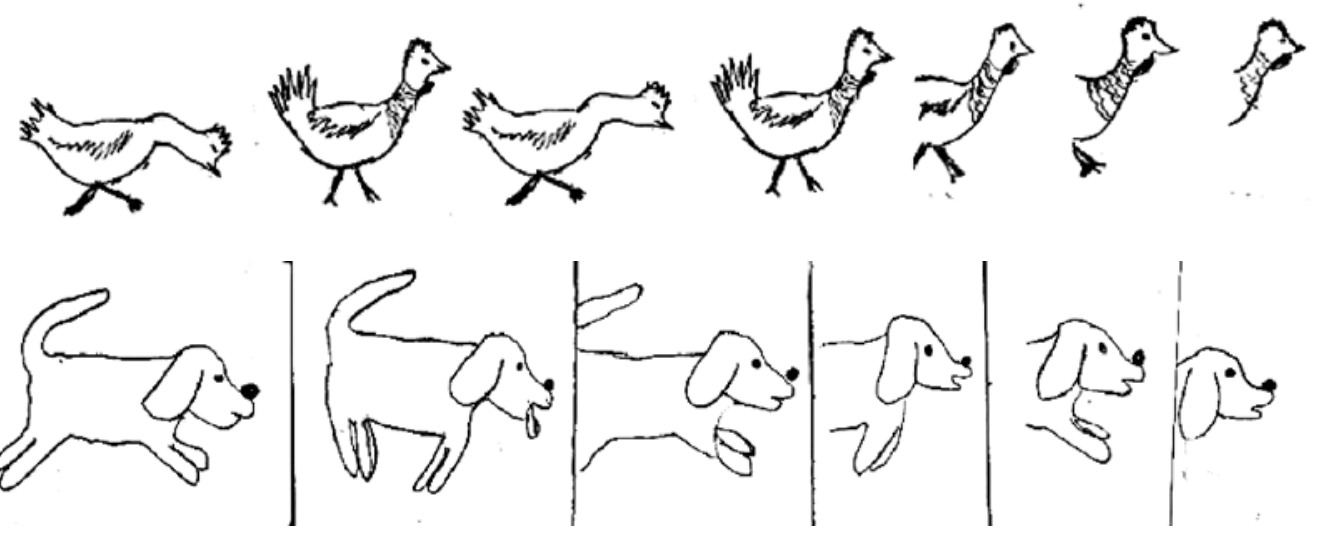

Desenhos da galinha e do cachorro, que fizeram parte da animação sobre o meio rural - animais da fazenda. A galinha ciscando ao caminhar, o cachorro fatigado com a língua para fora e as patas em movimentos alternados. 


\section{(RE)DESENHANDO A CIÊNCIA}

Alguns dos desenhos realizados nas fases 1 e 2, em cujas concepções científicas foi possível identificar movimentos - galinha ciscando, vacas e bois correndo no pasto, a representação da respiração de peixes na água, a evolução da vida marinha para a vida terrestre, o movimento de dinossauros predadores -, foram utilizados na produção de vinhetas de abertura dos programas em vídeo feitos pelos alunos. Os desenhos ganharam vida através da computação gráfica, num esforço da Arte-educadora e pesquisadora do grupo.
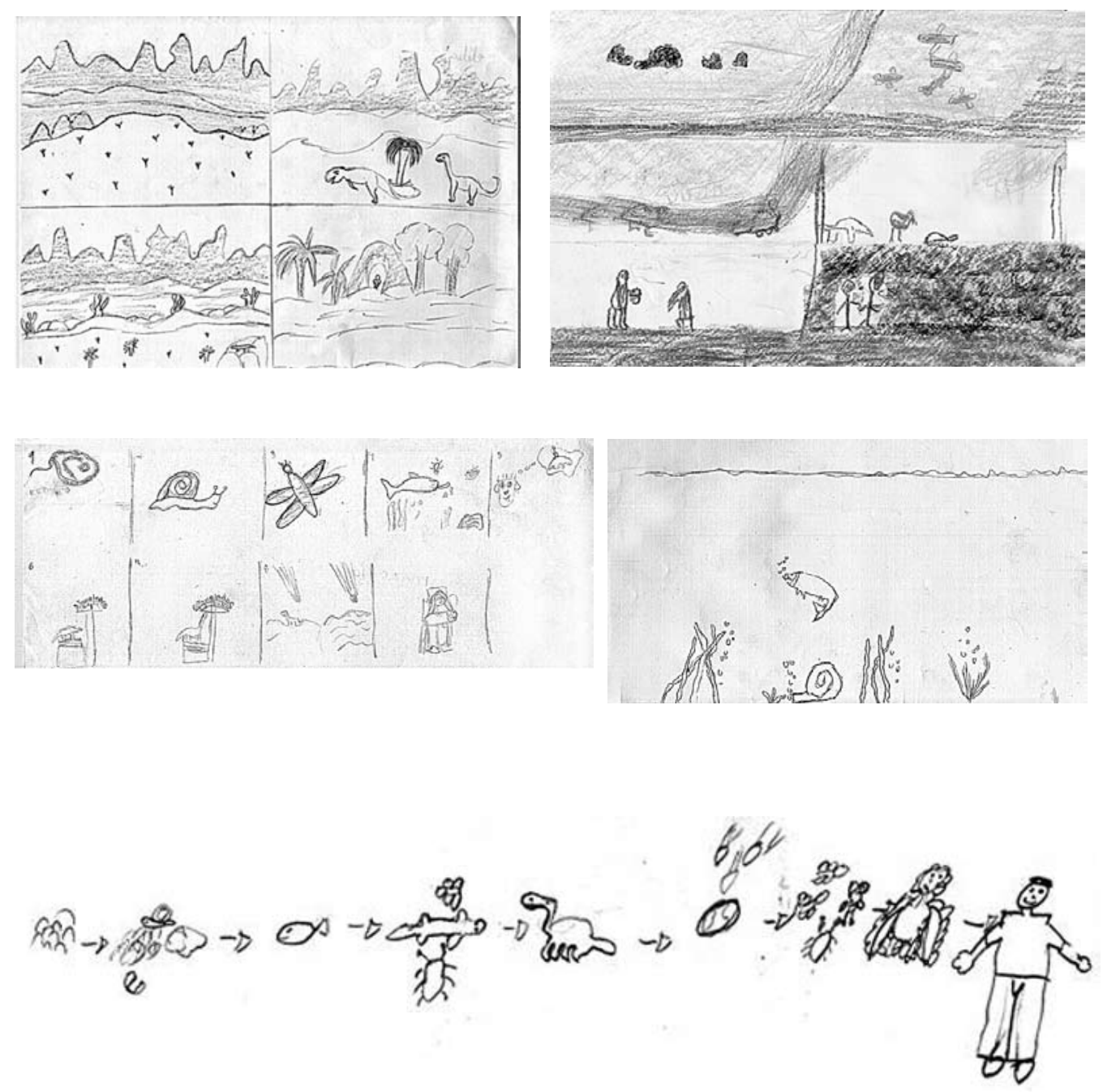

9. BORTOLIERO, S. A produção de vídeos educacionais e científicos nas universidades brasileiras. Comunicarte, Campinas: PUCCAMP, p. 85-99, 2003.

Com a participação da professora de Português da escola Frederico Peiró, os alunos iniciaram uma pesquisa, dentro dos temas escolhidos, para a produção dos vídeos, redigiram textos, confeccionaram roteiros e deram início às atividades de gravação ${ }^{9}$.

As gravações de imagens foram realizadas em momentos diferentes pelos grupos e acompanhadas pela equipe de pesquisadores e professoras da escola, 

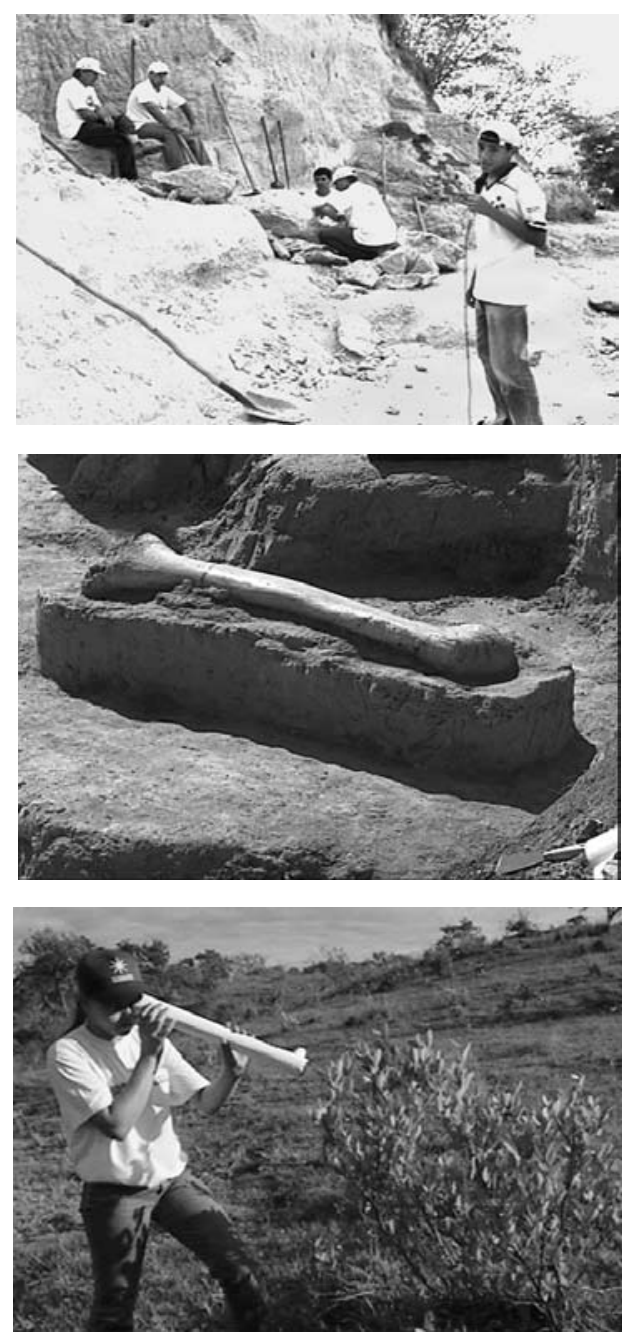

limitadas quase sempre ao perímetro que circunda a comunidade de Peirópolis. Como cenário, o grupo que realizou o vídeo "Dinossauros", escolheu a região de escavação de fósseis para centralizar a temática selecionada. O repórter científico mirim realizou uma série de entrevistas com os técnicos nas escavações, tendo grande dificuldade em associar imagens e textos. O grupo que produziu o vídeo “Águas de Peirópolis" se limitou a descrever como são formadas as cachoeiras e chamou a atenção para o problema relacionado à poluição dos rios, aproveitando que a equipe de gravação se deparou com um saco de lixo jogado na beira do rio durante a exploração do local. Nesse vídeo há uma breve apresentação sobre a geologia do lugar e as espécies de plantas que vivem no entorno da cachoeira. "Mundo Rural" foi o vídeo com maior quantidade de gravações externas. É rico em detalhes e descreve a história dos cavalos no mundo, a vida de porcos e galinhas, além de possuir uma longa entrevista com um tratador de animais.

\section{O COMPROMISSO SOCIAL NA PESQUISA CIENTÍFICA}

Entre os locais já diagnosticados no Brasil, a comunidade de Peirópolis vem obtendo uma série de benefícios e de melhorias em seu padrão de vida, e isto está diretamente relacionado às pesquisas paleontológicas na região. A atividade possibilitou um aumento de renda, ora como resultado do turismo, ora diretamente relacionado à geração de empregos. Atualmente, a maioria dos técnicos que trabalha nas escavações no período de seca são os próprios moradores do lugar. Nos meses de chuva, tornam-se responsáveis pelos cuidados com o museu e pela limpeza dos fósseis oriundos das escavações. As mulheres da comunidade se organizam na produção de doces artesanais e nas plantações, colhendo frutas como goiaba, mamão, figo, abóbora, matéria-prima de doces caseiros, gerando mais empregos a cada ano. Os jovens da comunidade já se preocupam com a formação de guias mirins para acompanhar os turistas. Os pesquisadores acabaram por exercer forte liderança na preservação do local e na educação científica da comunidade, porém ainda estão distantes de projetos que valorizem o desenvolvimento sustentável da região, já que a vinda de tu- 
ristas tem aumentado de forma significativa e o local não está preparado para receber um número grande de visitantes.

O compromisso de nosso grupo de pesquisadores com a comunidade foi justamente facilitar e favorecer o elo entre as instituições: o museu pode ser usado pela escola como espaço não-formal de ensino de forma sistemática, principalmente porque há carências de infra-estrutura e de materiais pedagógicos dentro da escola municipal. Os professores perceberam que é possível realizar experimentos científicos junto à natureza, abundante no local, e os vídeos de divulgação científica, sob a ótica dos jovens da comunidade, podem ser vistos e discutidos por outros estudantes de escolas rurais na região.

\section{UM DIAGNÓSTICO DOS RESULTADOS}

A divulgação científica, nesse projeto, realizada em forma de vídeos, tornase um instrumento facilitador da educação científica de nossos jovens desde que possa ser idealizada por eles em seu cotidiano.

Todas as atividades desenvolvidas como o desenho, a animação gráfica e o roteiro desses vídeos trazem as concepções científicas dessas crianças acerca dos dinossauros, do cotidiano das áreas rurais onde vivem, do meio em que a escola está inserida, ou seja, as imagens nos remetem aos rios, às plantas e aos animais do lugar.

O processo de produção dos trabalhos envolve relações de prazer e de cooperação, tanto para alunos como para professores. Assim, verificamos inúmeras possibilidades de métodos de como produzir vídeos de divulgação científica no contexto escolar. Pudemos perceber que alunos de 12, 13 e 14 anos são extremamente capazes de elaborar e produzir projetos comunicativos e participativos ${ }^{10}$.

Observamos, além da curiosidade, caminhos próprios na articulação das idéias, na construção de conhecimentos e nas formas de agrupamento por afeto. As atividades individuais de desenho em papel resultam no trabalho coletivo que surge através das animações. Outro aspecto observado é que as linguagens de televisão são apropriadas de forma tradicional. Os alunos reproduziram modelos conhecidos e veiculados por emissoras sobre as representações da vida reprodutiva dos animais do campo e as estruturas simbólicas. Os três grupos decidiram optar pelo diálogo com seu cotidiano mediante imagens que vão surgindo no roteiro. São galinhas, cavalos, porcos, os rios, as cachoeiras, a vegetação, as rochas e, finalmente, os fósseis. Estes elementos estão presentes no cotidiano da escola e nas casas localizadas em fazendas próximas. As técnicas apresentadas, como o uso de câmeras, permitiram o livre pensar sobre as coisas

10. BORREGO, C. Perspectivas sobre la alfabetización audiovisual. Cultura audiovisual, Cultura escolar. Sevilla: Diada editora, 2000. p. 5-20. (Série Investigación en la escuela). e, a partir daí, discuti-las, escrever e representar graficamente, com o corpo, com a voz e principalmente com o desenho.

Por outro lado, ao analisar os desenhos verificamos que todos os jovens sujeitos de nossa pesquisa compreendem que a descoberta de fósseis possibilitou a concretização de um Museu dos Dinossauros aberto à visitação pública desde 
meados da década de 1990 e que a pesquisa paleontológica foi responsável direta pela geração de empregos na comunidade. A pesquisa científica contribuiu com a cidadania na medida em que aumentou a renda das famílias rurais. Tivemos no elemento curiosidade um aliado para o aprendizado, sendo que a novidade surgiu nas formas de lidar com os equipamentos de vídeo, mola propulsora da motivação dos jovens durante o treinamento técnico.

Houve inúmeras contribuições nas décadas de 1970 e 1980 acerca de como os jovens constroem e transformam suas concepções sobre fenômenos naturais ou não ${ }^{11}$. Os sujeitos da pesquisa receberam informações de professores, do guia do museu, dos técnicos nas escavações, visitaram as escavações, observaram a natureza e tiveram acesso às informações vindas de diferentes fontes. A partir de suas experiências construíram formas próprias para divulgar o que apreenderam. Os saberes trazidos para a escola foram elementos respeitados na trajetória de produção dos vídeos.

"A idéia de que os alunos nada sabem antes de serem ensinados tem sido vigorosamente questionada. Estas idéias que não coincidem com o saber científico são designadas pelos pesquisadores como concepções, conceitos ou idéias intuitivas, ingênuas, espontâneas, alternativas ou de senso comum."12

Nos trabalhos de divulgação científica, não levamos em conta algumas dessas reflexões propostas por educadores em ciências, pois se tais conceitos conseguem explicar os fatos e auxiliam as pessoas com ações e se encontram fortemente assentadas na experiência pessoal, então é difícil imaginar simples mudanças de hábitos e de atitudes ante as formas propostas pela divulgação científica via meios de comunicação de massa.

Mas o aspecto mais relevante da descoberta das concepções espontâneas é o de que elas influenciam de maneira inexorável a aprendizagem das crianças em ciências. Perkins e Salomon ${ }^{13}$ lembram que "fenômeno de transferência de conhecimento acontece quando o conhecimento ou a habilidade conectada ao novo contexto enriquece e aumenta o grau de compreensão e entendimento da relação entre novas informações”. Essa relação age como estimulante e geradora de novas compreensões e conhecimentos. Pesquisas revelaram que, se as aulas de ciências não forem efetivas, a aprendizagem não será significativa, de maneira que as concepções espontâneas permanecem inalteradas mesmo após um ano letivo, ou até toda uma vida escolar. Mais do que isso, experiências conduzidas com alunos universitários da área de ciências naturais revelam que eles também carregam grande parte de suas concepções espontâneas quando não estão em situações acadêmicas. Enfim, concepções espontâneas influenciam a aprendizagem em ciências e se configuram como muito resistentes às mudanças; e mesmo quando se espera que elas estejam definitivamente dominadas pela ação da escola, podem ressurgir em outro contexto, mostrando que, de fato, toda a vida escolar, incluindo o ensino superior, pode ser incapaz de mudar a idéia que nós temos dos fenômenos do nosso mundo natural.

Se para os educadores as concepções espontâneas fazem parte do cotidiano da escola, no campo da divulgação científica são raros os trabalhos acadêmicos
11. DRIVER, R. et al. Dando sentido a la ciencia en secundaria: investigaciones sobre las ideas de los niños (Conferindo sentido à ciência na secundária: investigações sobre as idéias das crianças). Trad. María José Pozo Municio. Madrid: Aprendizaje Visor, 1994.

12. CHASSOT, A. A ciência através dos tempos. 8. ed. São Paulo: Moderna, 1994. p. 17

13. PERKINS, D. N.; SALOMON, G. Teaching for transfer (Transferência de aprendizagem). Educational Leadership 46(1), p. 22-23, 1988. 
que se debruçam para analisar de que forma as crianças e os jovens expressam suas concepções acerca de fenômenos científicos. O desenho, por exemplo, mania de nossas crianças, é pouco explorado como instrumento de análise e de compreensão do universo científico, quando falamos em divulgação científica.

O que percebemos na construção do conhecimento desses jovens de Peirópolis é que, apesar de as descobertas dos fósseis de dinossauros estarem inseridas no cotidiano dessas áreas rurais, restam ainda inúmeras dúvidas sobre sua existência, como desapareceram, como se alimentavam, como teria surgido o planeta; questões comuns em outras partes do país e do mundo. Nota-se a presença do ser humano no ambiente dos dinossauros, aspecto já diagnosticado também em outras partes do planeta.

Chassot $^{14}$ descreve a ciência como uma linguagem para facilitar nossa leitura do mundo, e essa linguagem é uma construção humana, logo mutável e falível. Para ele, nossos conhecimentos científicos são necessariamente parciais e relativos.

A pesquisa nos aponta como trabalhar com vídeos de divulgação científica no contexto escolar, principalmente quando alunos de 12, 13 e 14 anos de uma rede pública de ensino rural, carentes de materiais e de infra-estrutura, se dispõem a partilhar seus saberes para elaborar e produzir um projeto comunicativo. Ocorrem diferentes processos entre os grupos participantes no que se refere ao envolvimento afetivo com a proposta. O "querer" participar nos parece ser condição fundamental e o prazer do relato daquilo que é observado visto, tocado e sentido na natureza, foi outro fator de interação do trabalho.

Dinossauros fazem parte do patrimônio natural dessa região, mas aos jovens cabe associar tal dimensão com sua realidade diária. Após a produção dos vídeos, verificamos que o tema "Dinossauros" surge em apenas um dos grupos. $O$ roteiro final para edição nos mostra o uso dos desenhos (acessaram o banco de imagens) para explicar a origem da Terra e o aparecimento de dinossauros no planeta. Usam o formato entrevista em dois momentos: na reconstituição do passado da comunidade e para explicar a descoberta de fósseis. O outro tema escolhido, "Águas de Peirópolis", está diretamente associado ao universo do entretenimento e da diversão local. Mais tarde pudemos constatar que vários jovens estão interessados em se tornar guias turísticos, e as cachoeiras estariam nesse circuito. Mas o programa "Mundo Rural" descreve com exatidão a vida dos animais domésticos criados nas fazendas ou sítios onde residem. Vemos galinhas, cavalos, porcos e vacas sendo expostos numa mescla de saberes vindos do campo e da escola.

Ao se tornarem manipuladores de sua própria imagem na televisão, construída inicialmente em grupo através de roteiros feitos na sala de aula, baseados ora em pesquisa na comunidade (histórias de vida), ora por meio de revistas e livros, verificamos a valorização da auto-estima e do aprender brincando. Damos "um passo" na busca pela alfabetização audiovisual a partir do momento em que desmistificamos as técnicas de operação e manuseio de câmeras e microfones. Assim como em outras experiências já relatadas por pesquisadores, 
também observamos que a essência do trabalho em grupo favorece o senso da responsabilidade e organização. Mas apesar de nos mantermos inicialmente preocupados com o básico da linguagem em televisão, percebe-se em alguns jovens a criatividade de linguagens, mas há na maioria uma sensação de felicidade de realizar formatos semelhantes aos vistos na TV.

Alunos de escolas rurais são carentes de informações em todos os sentidos. A televisão ainda é a única forma de diversão desse grupo, a maioria nunca foi ao cinema, não joga videogame, não usa computador, nunca foi ao teatro e principalmente tem pouco acesso a livros. A interação observada nos grupos que produziram os vídeos favoreceu nessa escola rural um processo de alfabetização audiovisual, pois para tais alunos, excluídos da cultura tecnológica em evidência nos grandes centros urbanos, conhecer as técnicas e poder usá-las pressupõe o pensar em grupo.

Quanto ao conteúdo expresso nos trabalhos em vídeo, mesmo que tenham sido escolhidos, pensados, escritos, elaborados pelos jovens participantes do projeto, vale ressaltar que "a aprendizagem de conceitos científicos parece requerer inúmeras etapas em que as idéias iniciais são gradativamente complementadas, ampliadas, testadas, reformuladas, rejeitadas, substituídas, num processo complexo que se estende indefinidamente. Assim, por exemplo, o conceito de cidadania certamente continuará sendo reformulado ao longo de toda a vida de um indivíduo, conforme esse indivíduo vai refletindo e tendo contato com uma imensa variedade de novos contextos práticos e teóricos"15.

O mesmo ocorre com as formas de expressão desses jovens ao produzirem vídeos de divulgação científica. Outros trabalhos teriam que ser realizados com os mesmos objetivos para que avaliássemos os conceitos apreendidos ou não. Os alunos, a partir de suas experiências com fenômenos naturais, seres vivos, pessoas, informações da mídia (como foi o caso das atividades propostas nesta pesquisa), constroem por si mesmos uma variedade de teorias acerca das coisas da natureza.

"Se as idéias dos alunos, ainda que cientificamente inaceitáveis, têm-se mostrado úteis na vida cotidiana, no sentido de satisfazer necessidades de explicação de fatos ou de permitir previsões que auxiliem a escolha de modos de ação ante a realidade, estando, por outro lado, firmemente assentadas na experiência pessoal, então é difícil que as práticas escolares tradicionais consigam transformá-las." ${ }^{16}$

Não há, portanto, uma definição acabada de como o campo da comunicação científica poderia auxiliar os professores de Ciências na busca da alfabetização científica, da educação científica e da formação de uma cultura científica, termos comuns utilizados pelos educadores. Mas existem mecanismos que podem viabilizar a produção de produtos com caráter de divulgação científica, realizados por jovens aprendizes na busca do entendimento sobre "as coisas da ciência". O que fica evidente é a necessária relação de interdisciplinaridade entre as diferentes formas de manifestação artística desses jovens, para explicar fenômenos científicos e a interface dos saberes oriundos da comunicação e da educação em benefício da formação de uma cultura científica nas regiões rurais do Brasil.
15. DRIVER, R. et al., op. cit.

16. OSBORNE, R. J.; WHITTROCK, M. C. Learning science: a generative process (Ciência da aprendizagem: um processo generativo). Science Education 67(4), p. 489-508, 1983. 
Resumo: Através da manipulação de imagens como desenhos, uso de recursos de animação gráfica e da produção de vídeos de divulgação científica, um grupo de jovens da sexta série do ensino fundamental da escola rural Frederico Peiró da comunidade de Peirópolis, distante $30 \mathrm{~km}$ de Uberaba, no Triângulo Mineiro, expressa suas concepções científicas espontâneas sobre a formação geológica da Terra, o surgimento de dinossauros, a reprodução e alimentação de animais rurais e o entendimento sobre poluição na comunidade onde estão inseridos. As concepções espontâneas desses jovens acerca de temas científicos associados às diferentes atividades propostas pela pesquisa resultaram em três vídeos de divulgação científica: Dinossauros, Águas de Peirópolis e Mundo Rural. Os vídeos foram produzidos e idealizados no período de julho de 2000 a julho de 2001, com suporte técnico e apoio de pesquisa da Pró-Reitoria de Pesquisa e Extensão da Universidade de Uberaba no Estado de Minas Gerais.

Palavras-chave: divulgação científica, concepções espontâneas, educação para as Ciências/ensino de Ciências.
Abstract: Trough manipulation of images such as drawings, the use of graphic animation and video making resources for scientific publishing, a group of teenagers who attend 6th level of elementary school at Frederico Peiró rural school situated in Peirópolis community, $30 \mathrm{~km}$ far from Uberaba in Triângulo Mineiro county, express their spontaneous scientific conception regarding the geologic formation of the Earth, the arising of dinosaurs, reproduction and feeding of rural animals and the understanding of pollution in their community. The spontaneous conception of those teenagers about scientific themes associated to different activities proposed resulted in three videos for scientific publishing: Dinossauros, Águas de Peirópolis and Mundo Rural. The videos were idealized and produced between july/2000 and july/2001, under technical and research support of Pró-Reitoria de Pesquisa e Extensão at Universidade de Uberaba in Minas Gerais.

Keywords: scientific publishing, spontaneous conception, Education for Science/ Science teaching. 